DOI: 10.20472/IAC.2018.036.051

\title{
BHARATI WUKKADADA
}

K.J. Somaiya Institute of Management studies \& Research, India

DAVENDRANATH JHA

K.J. Somaiya Institute of Management studies \& Research, India

CHAITANYA PATEL

K.J. Somaiya Institute of Management studies \& Research, India

\section{IMPACT OF ON-PAGE HTML ELEMENTS ON SEO RANKINGS}

\begin{abstract}
:
The digital statics of Indian economy has impressive trends since last few years. With 62 million internet users and the penetration of $34.8 \%$, there has been lot of development in computer hardware and internet space. This development has helped India to resolve the problems like unavailability of reasonable and faster internet access. As the customer base of smart phones is increasing rapidly, the manufacturers have been able to manufacture high quality smart phones in lesser price. With the growing growth shown by the mobile operators and Service providers - Digital Marketing is fast coming up as an impressive way for direct marketing to the potential customer. This paper targets to catch the most preferred element to be inserted onto the On-page SEO elements, which impact the User behavior. The paper also aims to uncover the demographic profile, related facts and preferences of the customer and the on-page elements they prefer so as the search engine optimization (SEO) strategy can be formulated on the results. Beside with these objectives the study attempts to apprehend the impact of digital on-page HTML elements on the search engine optimization (SEO). Primary data has been collected with the help of Google Analytics and the User behavior before and after the implementation has been observed and then its impact on the SEO has been studied. For analysis data, Regression statistics has been used. Finally the findings are presented in a summarized manner for understanding the impact of the HTML element tags.
\end{abstract}

\section{Keywords:}

on-page SEO, off-page SEO, HTML, Google analytics, Hypothesis, Social Media Marketing 